Johnson \& Wales University ScholarsArchive@JWU

Health \& Wellness Department Faculty

Publications and Research

College of Health \& Wellness

2013

\title{
Valuable occupational therapy fieldwork educator behaviors
}

\author{
KJ. Koski \\ University of Utah \\ Rebecca Simon \\ Johnson \& Wales University - Providence, Rebecca.Simon@jwu.edu \\ N R. Dooley \\ New England Institute of Technology
}

Follow this and additional works at: https://scholarsarchive.jwu.edu/health_fac

Part of the Medicine and Health Sciences Commons

\section{Repository Citation}

Koski, KJ.; Simon, Rebecca; and Dooley, N R., "Valuable occupational therapy fieldwork educator behaviors" (2013). Health \& Wellness Department Faculty Publications and Research. 31.

https://scholarsarchive.jwu.edu/health_fac/31 
See discussions, stats, and author profiles for this publication at: https://www.researchgate.net/publication/234157296

\section{Valuable occupational therapy fieldwork educator behaviors}

Article in Work · January 2013

DOI: 10.3233/WOR-121507 · Source: PubMed

3 authors:

20anette Koski

University of Utah

4 PUBLICATIONS 12 CITATIONS

SEE PROFILE

A Nancy Robert Dooley

Worcester State University

4 PUBLICATIONS 94 CITATIONS

SEE PROFILE

Some of the authors of this publication are also working on these related projects:

Rebecca L Simon

Johnson \& Wales University

1 PUBLICATION 9 CITATIONS

SEE PROFILE

Dissertation View project 


\title{
Valuable occupational therapy fieldwork educator behaviors
}

\author{
Kari Jeanette Koski ${ }^{\mathrm{a}, *}$, Rebecca L. Simon ${ }^{\mathrm{b}}$ and Nancy R. Dooley ${ }^{\mathrm{b}}$ \\ ${ }^{a}$ University of Utah, Division of Occupational Therapy, Salt Lake City, UT, USA \\ ${ }^{\mathrm{b}}$ New England Institute of Technology, Occupational Therapy Department, East Greenwich, RI, USA
}

Received 17 January 2011

Accepted 16 August 2011

\begin{abstract}
.
OBJECTIVE: The purpose of this study was to investigate fieldwork educator behaviors that are valuable from the perspective of Level II occupational therapy and occupational therapist assistant students and fieldwork educators.

PARTICIPANTS: 85 fieldwork educators and 37 students from Eastern and Western parts of the United States.

METHODS: The 5 competency categories of the Self Assessment Tool for Fieldwork Educator Competency were used as the basis for developing the survey items and data was analyzed with non-parametric statistics to check for differences among groups of respondents.

RESULTS: Students and fieldwork educators generally ranked the value of the behaviors in the survey as the same. There were differences noted between responses of level II students on first, second, and third placements regarding supervision behaviors of fieldwork educators. (Chi square $=6.59, p=0.04$ and Chi square $=7.95, p=0.02$ ).

CONCLUSION: The alignment of opinion of students and fieldwork educators is important in that it reinforces the common goal of academic programs, students, and fieldwork educators. More research needs to be done in order to understand the impact of placement order on the rankings of valued fieldwork educator behaviors.
\end{abstract}

Keywords: Student, academic fieldwork coordinator, characteristics, supervision

\section{Introduction}

Fieldwork education is a vital component of occupational therapy education that provides students with "hands-on" learning experiences as augmentation to didactic studies [2]. Fieldwork also provides students opportunities for professional socialization and practice experience to enhance their clinical reasoning [14]. Fieldwork educators are occupational therapy practitioners who provide training for occupational therapy students in addition to their workplace responsibilities related to client care and service provision. However,

*Address for correspondence: Kari Jeanette Koski, MS, OTR/L, Assistant Professor, Clinical, Clinical Education Coordinator, University of Utah, Division of Occupational Therapy, 520 Wakara Way, Salt Lake City, UT 84108, USA. Tel.: +1 801585 3133; Fax: +1 801585 1001; E-mail: Jeanette.koski@hsc.utah.edu. these occupational therapy professionals may or may not have had any formal training in educating adult learners or providing feedback to assist students' professional development. Optimal student learning in a real life practice environment is reliant on many factors, including the interpersonal relationship between fieldwork educator and student [7,17]. Students in the nursing professions report when they have a positive and supportive relationship with their preceptor, they are more likely to ask questions and actively seek feedback to apply to their own learning [17]. James et al. noted that when a student is supported using scaffolding techniques, the student "demonstrates that she has made a conceptual shift in her understanding" of the concepts being taught by the supervisor [11]. "Scaffolding" refers to method of structuring feedback to guide student's learning; an example would be when a student appears confused, a fieldwork educator may use verbal or visual cues to adapt an explanation. 
It is important to study what behaviors are essential for occupational therapy practitioners to demonstrate in their role as fieldwork educators, not only from their own perspectives, but also from the perspectives of the students they train. There is a lack of current research in the literature related to valued characteristics of fieldwork educators specific to the field of occupational therapy. A study published in physical therapy literature provides a list of model fieldwork educator behaviors for that profession [9]. Using a list of 43 behaviors that the authors generated, physical therapy student participants were asked to rank the importance of the behaviors in addition to reporting how frequently they observed the behavior demonstrated by their clinical instructor. The results from this study emphasized that the most important behaviors for their clinical instructors to exhibit were effective communication, interpersonal relations, and teaching behaviors. The student participants in this study also felt that those characteristics were the least apparent in their interactions with supervisors [9].

Hummell [10] used qualitative methods to study occupational therapy student perceptions related to Level I and Level II occupational therapy fieldwork supervision. Participants were 60 student members of the Occupational Therapy Student Association at the University of Sydney. Hummell analyzed characteristics of effective educators and factors that limit supportive supervision of fieldwork students. "Interpersonal skills" were cited as the most important factor that determined whether the fieldwork supervision was "effective" or "ineffective". Large caseloads were identified as an environmental factor that most limited the effectiveness of the fieldwork supervision experience. Hummell [10] suggested that more research be done on this topic over a wider geographical area.

Kautzmann [12] surveyed occupational therapy fieldwork educators across the United States regarding their attitudes and values toward teaching adult learners. The participants ranked 13 statements about teaching adult learners based on Knowles's principles of adult learning [13]. The highest rankings fell in the following areas: "1. respect for learner's feelings and ideas, 2. learning to function as a team member, 3. supervisor as a resource person and provides feedback" [12]. This study was limited in that it did not explore how the fieldwork educators applied these concepts nor did it address student perceptions.

Christie [7] noted that $90 \%$ of occupational therapy fieldwork educators and $86 \%$ of occupational therapy fieldwork students felt that supportive communi- cation and interpersonal skills were the most essential characteristics of effective fieldwork educators. Study participants were recruited from a variety of practice settings throughout the United States. The respondents completed open-ended questionnaires asking them to explore "distinguishing characteristics of the effective versus ineffective supervisor" [7]. This study began to identify the characteristics valued by both fieldwork educators and students in addition to those that were not effective. Since this data was collected 26 years ago and perspectives may have changed, the subject should be examined again.

\subsection{Purpose}

The purpose of this study was to determine what Level II fieldwork educator behaviors are most valued by students and fieldwork educators. Using a questionnaire based on the "Self Assessment Tool for Fieldwork Educator Competency" [3], student and fieldwork educator participants ranked behaviors of fieldwork educators in order of importance. There was no attempt to measure whether the behaviors actually occurred.

\subsection{Research questions}

1. What behaviors are considered most essential for fieldwork educators to demonstrate in their interactions with fieldwork students?

2. Are there significant differences in the way fieldwork educators and students rank the importance of fieldwork educator behaviors?

\section{Method}

\subsection{Questionnaire design}

Demographic questions were asked to allow researchers to compare and contrast information from different groups of respondents, not simply comparing students to fieldwork educators. Students were asked their birth year (to explore generational differences), their status as an occupational therapy or occupational therapy assistant student, and which fieldwork experience they were in at the time of the survey (first, second or third rotation). The fieldwork educators were asked to identify their level of education and number of years supervising students. All participants were asked to identify current state of residence to determine if geographical differences existed. The University of Utah Institutional Review Board approved the study. 


\subsection{Safecom}

The Self Assessment Tool for Fieldwork Educator Competency (SAFECOM) was used as a basis for the questionnaire. The SAFECOM [3] is viewed as the most current method of voluntary self-assessment by the American Occupational Therapy Association to determine one's abilities and competencies in the fieldwork educator role. The SAFECOM was an expansion by the American Occupational Therapy Association (AOTA) Commission on Education (COE) of an original document developed by Wisconsin Council on Occupational Therapy, intended as a self-appraisal of ideal behaviors of an occupational therapy fieldwork educator. The AOTA Representative Assembly (RA) adopted the SAFECOM as a professional development self-assessment tool in 1998. As an industry standard for success, the behaviors outlined on this tool were felt to be the most important to examine for the purposes of this study.

The SAFECOM competencies are broken into 5 categories: Administration, Evaluation, Education, Supervision, and Professional Practice. The SAFECOM utilizes a 5 point rating scale "from 1 (low proficiency to 5 (high proficiency) to aid in self-assessment" [3]. Initially, survey design included all 5 categories of competency with every specific behavior listed in each category. Participants were asked to rank each behavior individually. Statements were written exactly as posed in the SAFECOM and participants were asked to rank each in terms of importance.

Twenty students and faculty were chosen as a convenience sample by the researchers to complete a pilot survey. Participants were given two weeks to complete and return the survey electronically; 2 surveys were returned. Feedback from the respondents indicated that the length of the survey was a deterrent and all felt they did not have the time to complete each section. It was also stated that the format was burdensome as there were between 14-16 statements to rank per area.

The first two authors then re-designed the electronic survey by independently selecting five items within each competency category of the SAFECOM from each section that they deemed most relevant based on professional experience and feedback from colleagues and students in their regions. They then compared the list of items chosen. The items that appeared on both lists were chosen for inclusion in the survey. Consensus was reached on the remaining items through debate and feedback from other occupational therapy professionals (see Fig. 1). For the present study ranking was pre- ferred over rating because the researchers recognized that participants in the pilot study said all items were 'important'. Researchers wanted to determine which items in each competency category were most important. One additional question was added to the survey only for those respondents who had both occupational therapy and occupational therapy assistant practitioners at the practice site. Two items in this question assessed the perceived importance of collaboration and role delineation between occupational therapy and occupational therapy assistant practitioners. Participants rated these items on a 5-point Likert scale (see Fig. 1).

Study participants were recruited via academic fieldwork coordinators in two regions of the United States, east and west (divided by the Mississippi River). The researchers emailed academic fieldwork coordinators in their respective consortia and requested they pass the survey on to fieldwork educators in their area and to Level II students enrolled in their programs. Participation in the survey was voluntary and anonymous and participants received no compensation or reward. Fieldwork educator participants needed to be currently practicing occupational therapists or occupational therapy assistants who had been in practice for more than one year and had educated at least one Level II occupational therapy student. The fieldwork educator participants did not need to be supervising a student at the time of the study. Occupational therapy and occupational therapy assistant student participants needed to be in the process of completing their Level II fieldwork experiences. Additionally, all participants were required to be English speaking, as the survey was presented in English.

Twenty-four academic fieldwork coordinators were sent an email with the researchers' cover letter of instructions and request to assist by distributing the survey to fieldwork educators in their area as well as each student currently enrolled in fieldwork at their academic program. By the deadline, 72 surveys had been returned. Genesis Rehabilitation was contacted, as an additional resource to distribute the survey, and the student coordinator agreed to disseminate surveys to each person on their staff who had supervised students. With this additional request, the final number of surveys returned, was $122 ; 85$ of which were completed by fieldwork educators and 37 by Level II fieldwork students.

\section{Data analysis}

Analysis of results was performed using SPSS Graduate Pack 10.0 for Windows [15] with an alpha level of 
Please rank the following FW educator ADMINISTRATION behaviors in order of importance (1 being the most important, 5 being the least)

1. Documents an organized, systematic fieldwork program (e.g., fieldwork manual, weekly sequence of expectations, etc.)

2. Schedules formal and informal meetings with the student to guide the fieldwork experience

3. Collaborates with the student to develop student learning objectives

4. Knowledgeable in legal and health care policies that directly influence FW

5. Provides a complete orientation for student to fieldwork site (e.g., policies, procedures, student expectations, and responsibilities, etc.)

Please rank the following FW educator EVALUATION behaviors in order of importance (1 being the most important, 5 being the least)

1. Reviews the evaluation tool and expected entry-level expectations (e.g., behavioral objectives, weekly objectives, etc.) with student prior to mid-term and final

2. Assesses student according to performance standards based on objective information (e.g., direct observation, discussion with student, review of student's documentation, observation by others, etc.)

3. Facilitates student self-reflection and self-assessment throughout the fieldwork and evaluation process

4. Uses an evaluation process to advise and guide the student regarding strengths and opportunities for growth based on site-specific objectives

5. Completes and distributes in a timely manner all evaluations regarding student performance, including but not limited to the midterm and final evaluation

Please rank the following FW educator SUPERVISION behaviors in order of importance ( 1 being the most important, 5 being the least)

1. Presents clear expectations of performance throughout the fieldwork experience, appropriate to entry level OT practice (e.g., student OTA/OT role delineation, Level I/II fieldwork, practice environment, etc.)

2. Anticipates and prepares student for challenging situations

3. Provides the student with prompt, direct, specific, and constructive feedback throughout the fieldwork experience

4. Elicits and responds to student's feedback and concerns

5. Models appropriate professional behaviors when interacting with students, clients, and peers

Please rank the following FW educator EDUCATION behaviors in order of importance ( 1 being the most important, 5 being the least)

1. Collaboratively develops student and fieldwork learning contracts to support occupation-based fieldwork experience (develop outcome-based measurable learning objectives)

2. Sequences learning experiences to grade progression toward entry-level practice

3. Maximizes opportunities for learning by using planned and unplanned experiences within the fieldwork environment

4. Demonstrates sensitivity to student learning style to adapt teaching approach and facilitate learning process

5. Guides student integration of therapeutic concepts and skills

Please rank the following FW educator PROFESSIONAL PRACTICE behaviors in order of importance (1 being the most important, 5 being the least)

1. Uses a systematic approach to evaluation and intervention that is science-driven and focused on clients' occupational performance needs

2. Skillfully collects and analyzes clients' occupational profile and performance in order to develop and implement OT services

3. Articulates the rationale and theoretical model, frame of reference and/or therapeutic approach for OT services

4. Works to establish a collaborative relationship that values the client perspective including diversity, values, beliefs, health, and well-being as defined by the client

5. Addresses psychosocial factors across the OT practice setting as a reflection of a client-centered approach. Is open in discussing issues with the student

Please Rate the Following Behaviors (1 being not important, 5 being extremely important)

1. Collaborates with OT/OTA to provide evaluation, interpretation of data, intervention planning, intervention, discharge planning and documentation

2. Articulates and implements OTA/OT role delineations as relevant to practice setting

Fig. 1. The survey.

0.05 for all analyses. The Mann-Whitney test was used to test the null hypothesis that there are no significant differences in the way students and fieldwork educators rank the importance of fieldwork educator behaviors. This non-parametric test functions like a t-test for two independent samples [16]. Since the sections of the survey were meant to gather different types of information and there is no summing of scores, each of the five survey sections was analyzed separately. For analysis, geographic location by state was re-coded as a dichotomous variable to designate location East or West of the Mississippi.
The Kruskal-Wallis test was used when there were more than 2 sub-groups, for example in looking at differences in students rankings of important behaviors from first, second or third fieldwork placements. For the last question on the survey, descriptive analysis was used.

\section{Results}

Eighty-five fieldwork educators and 37 fieldwork students completed the survey. Fifty respondents were from the Eastern United States and 70 were from the 
West. Most fieldwork educators had more than five years experience supervising students $(65.9 \%)$. The fieldwork educator cohort included 15 certified occupational therapy assistants (COTAs), 39 bachelor's degree-level registered occupational therapists (OTRs), 30 master's degree-level OTRs and one OTR with a doctoral degree.

Since there were only 5 OTA student respondents, data from occupational therapy and occupational therapy assistant students were combined. Nine student respondents were completing their first fieldwork experience at the time of the survey, 20 were completing their second, and 5 their third. Three students did not respond to this question. While researchers were interested in possible generational differences within the student group, the small number of student respondents made this analysis inconclusive. The following is detailed information regarding the analysis of the data collected in each of the 5 competency categories.

\subsection{Administration behaviors}

Both student and fieldwork educator respondents ranked Administrative item, "knowledgeable in legal and health care policies that directly influence fieldwork" as least important in the administrative category. All other items in this category clustered together as equally important. The Mann-Whitney test revealed no significant differences between the responses of fieldwork educators and students, see Table 1.

The Kruskal-Wallis test revealed one administration item that was significantly different depending on the student respondents' fieldwork placement order. Students on their first Level II placement ranked administration item, "Documents an organized, systematic fieldwork program (e.g., fieldwork manual, weekly sequence of expectations, etc.)" as significantly less important than students in second or third placements (Chi square $=6.37, p=0.04$ ).

\subsection{Evaluation behaviors}

Student and fieldwork educator respondents ranked the evaluation item, "Assesses student according to performance standards based on objective information" as most important. Additionally, both student and fieldwork educator respondents strongly ranked evaluation item; "Uses an evaluation process to advise and guide the student regarding strengths and opportunities for growth based on site-specific objectives" as the least important amongst the evaluation items. The Mann-
Table 1

Mann Whitney $U$ test comparison of groups on rankings of SAFECOM items $(N=122)$

\begin{tabular}{|c|c|c|c|c|}
\hline Variable & Group & $\begin{array}{l}\text { Mean } \\
\text { rank }\end{array}$ & $\mathrm{u}$ & Sig. $^{\text {a }}$ \\
\hline \multirow[t]{2}{*}{ Administration 1} & Educators & 63.79 & 1462.5 & 0.53 \\
\hline & Students & 58.53 & & \\
\hline \multirow[t]{2}{*}{ Administration 2} & Educators & 60.86 & 1518.0 & 0.76 \\
\hline & Students & 62.97 & & \\
\hline \multirow[t]{2}{*}{ Administration 3} & Educators & 59.64 & 1414.5 & 0.36 \\
\hline & Students & 65.77 & & \\
\hline \multirow[t]{2}{*}{ Administration 4} & Educators & 63.91 & 1367.5 & 0.20 \\
\hline & Students & 55.96 & & \\
\hline \multirow[t]{2}{*}{ Administration 5} & Educators & 62.12 & 1520.0 & 0.76 \\
\hline & Students & 60.08 & & \\
\hline \multirow{2}{*}{ Evaluation 1} & Educators & 61.85 & 1542.5 & 0.86 \\
\hline & Students & 60.69 & & \\
\hline \multirow{2}{*}{ Evaluation 2} & Educators & 61.27 & 1553.0 & 0.91 \\
\hline & Students & 62.03 & & \\
\hline \multirow{2}{*}{ Evaluation 3} & Educators & 61.65 & 1559.5 & 0.94 \\
\hline & Students & 61.15 & & \\
\hline \multirow{2}{*}{ Evaluation 4} & Educators & 59.46 & 1399.5 & 0.32 \\
\hline & Students & 66.18 & & \\
\hline \multirow[t]{2}{*}{ Evaluation 5} & Educators & 63.12 & 1434.5 & 0.38 \\
\hline & Students & 57.77 & & \\
\hline \multirow{2}{*}{ Supervision 1} & Educators & 58.94 & 1354.5 & 0.21 \\
\hline & Students & 67.39 & & \\
\hline \multirow[t]{2}{*}{ Supervision 2} & Educators & 62.73 & 1468.0 & 0.54 \\
\hline & Students & 58.68 & & \\
\hline \multirow[t]{2}{*}{ Supervision 3} & Educators & 63.31 & 1419.0 & 0.37 \\
\hline & Students & 57.35 & & \\
\hline \multirow[t]{2}{*}{ Supervision 4} & Educators & 62.37 & 1498.5 & 0.67 \\
\hline & Students & 59.50 & & \\
\hline \multirow[t]{2}{*}{ Supervision 5} & Educators & 61.32 & 1557.5 & 0.93 \\
\hline & Students & 61.91 & & \\
\hline \multirow[t]{2}{*}{ Education 1} & Educators & 60.45 & 1483.0 & 0.59 \\
\hline & Students & 63.92 & & \\
\hline \multirow[t]{2}{*}{ Education 2} & Educators & 61.87 & 1541.0 & 0.86 \\
\hline & Students & 60.65 & & \\
\hline \multirow[t]{2}{*}{ Education 3} & Educators & 59.07 & 1366.0 & 0.23 \\
\hline & Students & 67.08 & & \\
\hline \multirow[t]{2}{*}{ Education 4} & Educators & 63.62 & 1392.0 & 0.30 \\
\hline & Students & 56.62 & & \\
\hline \multirow[t]{2}{*}{ Education 5} & Educators & 63.09 & 1437.0 & 0.44 \\
\hline & Students & 57.84 & & \\
\hline \multirow[t]{2}{*}{ Practice 1} & Educators & 61.95 & 1534.0 & 0.83 \\
\hline & Students & 60.46 & & \\
\hline Practice 2 & Educators & 64.58 & 1311.0 & 0.13 \\
\hline & Students & 54.43 & & \\
\hline Practice 3 & Educators & 59.22 & 1379.0 & 0.25 \\
\hline & Students & 66.73 & & \\
\hline Practice 4 & Educators & 61.38 & 1562.0 & 0.95 \\
\hline & Students & 31.78 & & \\
\hline Practice 5 & Educators & 60.22 & 1463.5 & 0.53 \\
\hline & Students & 64.45 & & \\
\hline
\end{tabular}

all significance tests are 2-tailed.

Whitney test revealed no significant differences between student and fieldwork educator responses for these items. Respondents ranked the other behaviors in the evaluation section as having a similar level of importance. $(U=1542.5, p=0.86 ; U=1553.5, p=$ 
$0.91 ; U=1559.5, p=0.94 ; U=1399.5, p=0.32$; $U=1434.50, p=0.38$.)

\subsection{Supervision behaviors}

Student and fieldwork educator respondents ranked the Supervision item, "Provides the student with prompt, direct, specific, and constructive feedback throughout the fieldwork experience" as most important in this section. All respondents ranked the item; "Anticipates and prepares student for challenging situations" as the least important, followed closely by the item; "Elicits and responds to student's feedback and concerns." The Mann-Whitney test revealed no significant differences between student and fieldwork educator responses.

The Kruskal-Wallis test revealed that two items in the supervision section were significantly different depending on the student respondents' fieldwork placements. Students in first and third placements ranked the item, "Presents clear expectations of performance throughout the fieldwork experience, appropriate to entry level practice," as less important than students in second placements (Chi square $=6.59, p=0.04$ ). Students in first placements ranked the supervision item. "Anticipates and prepares student for challenging situations," as significantly more important than students in second or third placements (Chi square $=7.95, p=$ $0.02)$.

\subsection{Education behaviors}

Fieldwork educators ranked education item, "Maximizes opportunities for learning by using planned and unplanned experiences within the fieldwork environment", as the most important behavior in the education section. Students ranked this item as second in importance, after the item, "Demonstrates sensitivity to student learning style to adapt teaching approach and facilitate learning process." The Mann-Whitney test, however, revealed no statistically significant differences between the groups. $(U=1483, p=0.59$, $U=1541, p=0.86, U=1366, p=0.23 ; U=1392$, $p=0.30 ; U=1437, p=0.44$.) The item, "Collaboratively develops student and fieldwork learning contracts to support occupation-based fieldwork experiences," was ranked as least important by both students and fieldwork educators.

\subsection{Professional practice behaviors}

Student and fieldwork educator respondents were in agreement that the item, "Works to establish a collaborative relationship that values the client perspective including diversity, values, beliefs, health, and well-being as defined by the client" was the most important behavior in this section. The pattern of rankings in this section was extremely similar for students and educators. The item ranked as second most important in this section, "Skillfully collects and analyzes clients' occupational profile and performance in order to develop and implement OT services," was rated more strongly by students than fieldwork educators. The Mann-Whitney test revealed no significant differences between groups, however. $(U=1534, p=0.83 ; U=1311, p=0.13$; $U=1379, p=0.29 ; U=1562, p=0.95 ; U=1463$, $p=0.53$.)

Descriptive analysis was completed for the two questions about OT/OTA relationships. Of the 79 respondents whose work site employed both OT and OTA staff, $78(87 \%)$ rated the statement, "Collaborates with OT/OTA to provide evaluation, interpretation of data, intervention planning, intervention, discharge planning and documentation" as either very important or extremely important. Seventy-two respondents, 58\%, rated the second statement, "Articulates and implements OTA/OT role delineations as relevant to practice setting," as very important or extremely important.

\section{Discussion}

Overall, the findings that students and fieldwork educators value fieldwork educator behaviors at similar levels are encouraging for the profession. The most valuable behaviors centered on the fieldwork educator's active role in providing feedback, serving as a role model, and teacher. These were:

- Documents an organized, systematic fieldwork program (e.g., fieldwork manual, weekly sequence of expectations, etc.)

- Schedules formal and informal meetings with the student to guide the fieldwork experience

- Collaborates with the student to develop student learning objectives

- Provides a complete orientation for student to fieldwork site (e.g., policies, procedures, student expectations, and responsibilities, etc.) 
- Assesses student according to performance standards based on objective information (e.g., direct observation, discussion with student, review of student's documentation, observation by others, etc.)

- Uses an evaluation process to advise and guide the student regarding strengths and opportunities for growth based on site-specific objectives

- Provides the student with prompt, direct, specific, and constructive feedback throughout the fieldwork experience

- Elicits and responds to student's feedback and concerns

- Maximizes opportunities for learning by using planned and unplanned experiences within the fieldwork environment

- Demonstrates sensitivity to student learning style to adapt teaching approach and facilitate learning process

- Works to establish a collaborative relationship that values the client perspective including diversity, values, beliefs, health, and well-being as defined by the client

High value was placed on the supervisor acting as a 'director' of the learning experience, collaborating and communicating with the student and clients in a positive manner. This finding is important since the primary role of a supervisor is to "maintain the provision of quality care for individuals receiving services while simultaneously facilitating learning" [6]. This is also consistent with Christie [7] findings that students valued supportive communication and interpersonal skills in fieldwork educators.

The results of the present study indicate that students value different fieldwork educator behaviors depending on which Level II placements they are completing. Students on their first placement noted the value of the fieldwork educator anticipating and preparing them for challenging situations. Students on their second and third placement valued more organization from the fieldwork site in the form of a fieldwork manual, weekly expectations etc. This finding is significant in that academic fieldwork coordinators and fieldwork educators generally view the order of placements in terms of their perceptions of the students' ability, confidence, and evaluation/intervention skills and not necessarily in terms of the student's perceptions.

Barnes and Thornton [6] and Costa [8] describe the process of supervision and learning within the formation of the supervisory relationship as a developmental cycle in keeping with Hershey and Blanchard's [18]
Situational Leadership model. As such, the nature of the supervisory process shifts in accordance with the students needs. A 'directing' phase is seen as necessary for the student initially. The supervisory role becomes increasingly indirect (coaching, supporting, delegating) as the student's skills and supervisory relationship builds [6]. Generally, in Level II fieldwork, this is a process which occurs over time within the context of the supervisory relationship and specific practice environment. If there is a shift in the context (i.e., more complex client situation), the supervisory process may revert to a directing phase regarding a specific supervisee need (i.e., for more direction about how best to proceed).

Initially the student is unfamiliar with the tasks necessary to perform the OT practitioner role. The supervisor knows the tasks required and will work closely with the student to set the structure of the day. This 'directing' phase is valuable for the student initially and may be why, in part, the situational leadership model appears consistent with our findings. Results from the present study suggest both the fieldwork educator and the student value direction; therefore, emphasis should be placed on preparing the student for a variety of situations, especially in their initial fieldwork placement. The situational leadership model also identifies the 'coaching' phase in which the supervisor and student begin to expect more from the student and there is more emphasis on discussion and student opinions. This is a time of decreased confidence for the student [6]. This may explain the finding in the present study that students on second and third experiences (where supervisors are more likely to expect that they are in this phase) value more concrete direction and organization of the environment in which they are to treat.

This finding highlights the potential need for fieldwork educators to be more conscious of providing different levels of support depending on placement and experience of the student. Results also suggest emphasis be placed on preparing the student for a variety of situations, most notably in their initial Level II fieldwork placement.

In examining the evaluative functions of a fieldwork educator, participants gave the least weight to the item, "Uses an evaluation process to advise and guide the student regarding strengths and opportunities for growth based on site-specific objectives." This may provide insight to what academic fieldwork coordinators perceive as an on-going struggle in making sure site-specific learning objectives are provided to academic programs 
by every fieldwork setting. Accreditation Council for Occupational Therapy Education (ACOTE) standards state that academic programs must, "Demonstrate that academic and fieldwork educators collaborate in establishing fieldwork objectives, identifying site requirements, and communicating with the student and fieldwork educator about progress and performance during fieldwork" [15]. Based on responses in the current study, more research is needed to assess fieldwork educators' and students' understanding the value of these objectives. More information may assist with determining the best method of developing and utilizing objectives on site.

Although the difference was not significant in this case, students were apt to rate the practice item about using information regarding clients' occupational performance as more important than fieldwork educators. This difference would need to be explored in future studies in more detail and with larger samples. It may reflect a continued disconnect between the occupationbased approach to occupational therapy practice that is being taught in educational programs and the traditional methods used in practice which may, in part, be dictated by reimbursement or practice setting.

Just as, historically, we saw those who founded occupational therapy based on use of arts and crafts and a 'holistic' brand of occupational therapy conflict with those who were more reductionist in nature [1], the trend continues today. It seems the pendulum has swung once again from this craft-based therapy, to a more medical model, and back to a more holistic, occupationsbased approach. A difference in language and labeling naturally occurs between those in the field and those emerging into practice and may also create a difference in perception of what is valuable.

Language also becomes pivotal in this discussion. Our professional language adjustments brought about by the transition from Uniform Terminology [5] to The Occupational Therapy Practice Framework: Domain and Process, 2nd edition [4], continue to reflect the paradigm shift that is happening in the profession. The difference in responses may simply be because respondents were speaking a different "language".

Another point to be considered in the current study is that the majority of fieldwork educators who completed the survey were experienced in working with fieldwork students: $65.9 \%$ had done so for more than five years. Also, those who chose to participate in the study may have characteristics related to their interest in fieldwork education that made them decide to participate. Perhaps the findings would be somewhat different if there were more new fieldwork educators included.

\section{Future research}

The authors recommend further research into perspectives of fieldwork educators, students, and academic fieldwork coordinators. As stated earlier, more research is also needed regarding the order of student placement and how the needs of such students change with each Level II experience. It has been previously thought that some sites prefer a student in their second or third fieldwork placement because of their enhanced level of experience. Some questions have been raised among academic fieldwork coordinators regarding placement order. It was anecdotally perceived that the student takes some newly learned professional skills with them to the second and third placement. The difficulty here may be that a more advanced skill set is then expected of the student, which may be unrealistic because they are in a completely different situation in terms of practice environment and supervisory relationship. Though the reasoning process of our profession is expected to generalize, the need for a student to become oriented to the setting is still likely a factor in terms of their need for direction.

More student data is needed to assist researchers in determining true perceptions and values related to fieldwork education. Future research could include students rating the frequency with which they perceive fieldwork educators carrying out the valued behaviors. Evidence from this study which suggested that students may have valued different fieldwork educator competencies depending on their order of placement should also be further explored.

Additional research comparing perceptions of novice and experienced fieldwork educators would also be of interest. Perhaps there would be discrepancies in how much time or perceived effort fieldwork educators feel they put into the behaviors and the resulting student fieldwork success or failure rates depending on the number of students they have educated.

Lastly, the authors encourage research regarding the techniques utilized by academic fieldwork coordinators to assist fieldwork educators to develop and maintain the behaviors that students value. It would also be of interest to learn about how academic fieldwork coordinators educate occupational therapy and occupational therapy assistant students as to why these behaviors will help them grow professionally.

\section{Conclusion}

The researchers feel the competencies detailed in the SAFECOM are important and individual fieldwork 
educators have their own areas of specialty and skill. However, it is important to be able to prioritize areas to focus education and support efforts of fieldwork educators. One of the most notable pieces of this study is that the opinions of the students and the fieldwork educators are so closely aligned. There is a great deal more research to be done in the occupational therapy field regarding fieldwork education and the best practice regarding educating our future occupational therapy colleagues.

\section{Acknowledgements}

The authors would like to thank their colleagues and program chairs in each of the respective educational institutions. Special thanks to Donna Costa, DHS, OTR/L, FAOTA, Assistant Professor, Clinical, University of Utah, for the inception of this project and support throughout the process; Thomas R. Thibodeau, Assistant Provost, New England Institute of Technology, for his technical support of the electronic surveys; Estelle Strydom, OTR/L Clinical Specialist of Education and Staff Development of Genesis Rehabilitation for assisting us with the additional survey distribution; and Mary Alicia Barnes, OTR/L, Fieldwork Coordinator, Tufts University, Department of Occupational Therapy for invaluable editing assistance.

\section{References}

[1] Agarwal S, Early MB, editor. Brief history of occupational therapy and role of the occupational therapy assistant in physical disabilities practice. 2 ed. [15]. American Occupational Therapy Association. Accreditation standards for a master'sdegree-level educational program for the occupational therapist. American Journal of Occupational Therapy. 2007; 61(6): 9.
[2] American Occupational Therapy Association. Occupational therapy fieldwork education: value and purpose. American Journal of Occupational Therapy. 2009; 63(6): 2.

[3] American Occupational Therapy Association. SelfAssessment tool for fieldwork educator competency. Bethesda 2009 [cited 2011 1/12/2011].

[4] American Occupational Therapy Association. The Occupational Therapy Practice Framework: Domain and Process. 2 ed. Bethesda: AOTA press; 2008.

[5] American Occupational Therapy Association. Uniform Terminology for Occupational Therapy. 3 ed. Bethesda: AOTA press; 1994.

[6] Barnes M, Thornton, AL, editor. The successful occupational therapy fieldwork student. Thorofare: Slack Incorporated; 2002.

[7] Christie BA, Joyce PC, Moeller PL. Fieldwork experience, part II: The supervisor's dilemma. The American Journal of Occupational Therapy. 1985; 39(10): 675-81.

[8] Costa D. Clinical supervision in occupational therapy: A guide for fieldwork and practice. Bethesda: AOTA Press; 2007. St. Louis: Mosby Inc; 2006.

[9] Emery MJ. Effectiveness of the Clinical Instructor. Physical Therapy. 1984; 64(7): 1079-83.

[10] Hummell J. Effective fieldwork supervision: Occupational therapy student perspectives. Australian Occupational Therapy Journal. 1997; 44: 144-57.

[11] James IA, Milne D, Morse R. Microskills of clinical supervision: Scaffolding skills. Journal of Cognitive Psychotherapy: An International Quarterly. 2008: 22(1): 29-36.

[12] Kautzmann LM. Clinical teaching: Fieldwork supervisors' attitudes and values. The American Journal of Occupational Therapy. 1990; 44(9): 197-200.

[13] Knowles M. The theory and practice of adult education. Chicago: Follett; 1980.

[14] Sladyk K. Clinical reasoning and reflective practice: Implications of fieldwork activities. Occupational Therapy in Health Care. 2000; 13(1): 12.

[15] SPSS, Inc. SPSS base 10.0 applications guide. Chicago: Author; 1999.

[16] SPSS, Inc. SPSS Graduate Pack (Version 10.0 for Windows). Chicago: Author; 1999.

[17] Zilembo M, Montresso L. Nursing student's perceptions of desirable leadership qualities in nurse preceptors: A descriptive study. Contemporary Nurse. 2008; 27(2): 12.

[18] Hersey P, Blanchard K, Johnson D. Management of organizational behaviour: Utilizing human resources. Upper Saddle River: Prentice Hall: 2000. 